\title{
ECIEN-2020 study: the effect of COVID-19 on admissions for non-COVID-19 diseases
}

\author{
Beatriz Ramos-Lacuey ${ }^{1}$. Mercedes Herranz Aguirre ${ }^{2,3,4}$. Clara Calderón Gallego ${ }^{1}$. \\ Andrea llundain López de Munain ${ }^{1} \cdot$ Eva Gembero Esarte ${ }^{3} \cdot$ Laura Moreno-Galarraga $^{1,4,5,6}$ (B)
}

Received: 9 September 2020 / Accepted: 13 December 2020 / Published online: 9 February 2021

(c) Children's Hospital, Zhejiang University School of Medicine 2021

\begin{abstract}
Background The pandemic caused by severe acute respiratory coronavirus 2 (SARS-CoV-2) has had great effects on health systems worldwide, not only in relation to coronavirus disease 2019 (COVID-19) cases but also affecting patients with other pathologies.

Methods ECIEN-2020 is an observational study conducted in a tertiary referral hospital in Navarra, Spain. It describes the effects of COVID-19 pandemic and the preventive measures adopted, in pediatric admissions for non-COVID-19 diseases. Admissions during March-June 2020 (first wave of the COVID-19 pandemic in Spain) are described and compared with the same quarter in 2019. A sub-analysis was performed delving into epidemiology. Patient characteristics (age, sex, past medical history), disease characteristics (symptoms, duration of symptoms, previous consultation in Primary Care Health Center), and admission characteristics (place and average stay) were analyzed.

Results A 33\% reduction in the number of pediatric hospital admissions was observed, decreasing from 529 hospitalizations in 2019 to 353 in $2020(P<0.001)$. This highlights a 48\% reduction in patients admitted for pulmonary diseases. There were no significant changes in average hospital-stay, percentage of intensive care unit admissions, or in admissions for other reasons. Percentage of patients admitted among those seen in the emergency department rose from 5.1\% in 2019 to $10.9 \%$ in 2020, whereas the total number of consultations in the emergency department decreased by $68 \%$.

Conclusion The pandemic and the measures adopted due to SARS-CoV-2 have significantly decreased pediatric admissions for non-COVID-19 diseases, especially due to a reduction in the hospitalization for respiratory diseases.
\end{abstract}

Keywords Admission $\cdot$ COVID-19 $\cdot$ Hospitalization $\cdot$ SARS-CoV-2

Laura Moreno-Galarraga

laura.moreno.galarraga@cfnavarra.es;

lauramoreno11@yahoo.es

1 Department of Pediatrics, CHN, Complejo Hospitalario de Navarra, Servicio Navarro de Salud, C/Irunlarrea 3, 31080 Pamplona, Spain

2 Pediatric Infectious Diseases Department, CHN, Complejo Hospitalario de Navarra, Servicio Navarro de Salud, Pamplona, Spain

3 Pediatric Hospitalization, Department of Pediatrics, CHN, Complejo Hospitalario de Navarra, Servicio Navarro de Salud, Pamplona, Spain

4 IdiSNA, Navarra Institute for Health Research, Pamplona, Spain

5 Department of Preventive Medicine and Public Health, School of Medicine, University of Navarra, Pamplona, Spain

6 Pediatric Pulmonology, Department of Pediatrics, CHN, Complejo Hospitalario de Navarra, Servicio Navarro de Salud, Pamplona, Spain

\section{Introduction}

On the 30th of January 2020, the World Health Organization (WHO) declared the disease (COVID-19) caused by severe acute respiratory coronavirus 2 (SARS-CoV-2) a global pandemic [1]. Since then, this coronavirus has spread rapidly and has caused enormous repercussions on economic and health-systems worldwide [2-4]. In Spain, due to the rapid increase of cases detected between February and March 2020, the Spanish Government declared a state of alarm on the 14th of March and established a situation of strict confinement, severe restrictions and lockdown throughout the country [5, 6]. This unprecedented situation, which lasted 99 days, was efficient in rapidly reducing the number of COVID-19 cases and the community transmission rate [7]; however, it also caused important health, social and economic repercussions. 
In Spain, the SARS-CoV-2, which is responsible for the COVID-19 disease [8, 9], caused a saturation of the public health system, leading to the collapse and saturation of hospitals and intensive care units, and causing extreme situations owing to the high number of patients and the limitations in material and human resources [3, 10]. The efforts and changes made to meet the growing demand for COVID19 cases indirectly caused changes in the care and management of other non-COVID-19 pathologies.

SARS-CoV-2 affects children, but multiple studies and previous publications have shown how it produces a milder and shortened condition in pediatric patients [11-17]. In many cases, children with COVID-19 remain asymptomatic and when symptoms appear, pediatric patients usually present a greater clinical variability. Children can present with the typical adults' symptoms, such as fever, cough and respiratory distress [18], but also with a wide range of different affections, such as skin lesions, cardiac, neurological or digestive symptoms $[11,12,19]$. Even though pediatric cases are generally milder, severe cases as well as complications and mortality have also been described [19-22].

Many studies have been published analyzing cases and case-series of COVID-19 in children, but this pandemic has also caused multiple changes in the attention of pediatric patients with other diseases (non-COVID-19) that deserve to be studied [10, 23-25]. Along with the exponential increase in the number of visits to the emergency department (ED) for symptoms suggestive of COVID-19, a decrease in the number of consultations for other reasons $[10,23]$ has been described.

The objective of the present study is to analyze and describe the epidemiology of admissions for non-COVID-19 pathologies in a pediatric hospital and to compare the situation experienced during the first wave of the COVID-19 pandemic (March-June 2020) with the same quarter in the year 2019 .

\section{Methods}

This work has been performed within the ECIEN-2020 study (from the Spanish "Efecto de COVID-19 en Ingresos por Enfermedades NO-COVID" or "Effect of COVID-19 on Admissions for non-COVID-19 Diseases"). This is an observational, cross-sectional analytical study, performed in the pediatric reference hospital in Navarra, Spain, which describes and compares admissions during the first wave of the COVID-19 pandemic, with admissions in the same period and same center of the previous year (2019). Navarra is located in the north of Spain; it has a population of over 660,000 habitants, of which 101,000 are children (0-15 years) [26]. The study evaluated changes in nonCOVID-19 admissions in the pediatric service of the
Complejo Hospitalario de Navarra (CHN Hospital), the tertiary reference public hospital for the Community.

SARS-CoV-2 caused more than 5000 confirmed adult cases and 300 confirmed pediatric cases between March and June 2020 in Navarra, with 528 adult deaths [27]. This quarter was considered the "first-COVID-19 wave". The second wave started in Navarra in August 2020, and cases are still rising (last data available November 2020). In the last week registered (week 43) Navarra presents a COVID-19 incidence rate of 595 cases $/ 100,000$ habitants and it is still following an increasing trend, placing Navarra as one of the most affected regions in Europe, reaching over 30,000 confirmed COVID-19 cases. In adults the highest hospital admissions rate was registered during the first wave, around week 12th (last week of March), reaching up to 100 COVID19 admissions per day [27, 28]. Admission rate in children was clearly inferior, showing 10 admissions per 100,000 children in Navarra during the first wave and a ratio of 1 admitted child for every 180 hospitalized adults [19]. During the pandemic a specific hospitalization ward was opened for pediatric COVID-19 admissions at CHN Hospital, while the usual $\mathrm{CHN}$ hospitalization pediatric ward was kept open for admissions for non-COVID-19 pathologies, maintaining the same personal and the same bed-capacity.

In the CHN pediatric service, about 40,000 consultations are attended every year in the ED, and 2000 children are admitted in the pediatric CHN service. In 2019, 40,870 children were attended in the ED, 1708 patients were admitted to the observation unit, 1883 were admitted to the general pediatric hospitalization ward, and 190 were admitted to the pediatric intensive care unit (PICU). Four other hospitals in Navarra have pediatric ED and pediatric hospitalization: two private centers (Universidad de Navarra Clinic and San Miguel Clinic) and two public centers located in Estella and Tudela (Reina Sofía Hospital and García Orcoyen Hospital). The CHN PICU is the only PICU in Navarra's public health system. The majority of the hospitalized children are attended in the CHN pediatric service in Pamplona, the capital, with the other hospitals accounting for about 400-600 pediatric admissions per year.

A retrospective search was performed on all pediatric patients $(0-15$ years) admitted to the $\mathrm{CHN}$ pediatric service during the study period. For this specific study, only non-COVID-19 patients were analyzed; a study describing hospitalized pediatric COVID-19 patients in Navarra has previously been published [19]. The number of visits to the pediatric ED, the total number of pediatric admissions in the $\mathrm{CHN}$, and the number of pediatric admissions in the observation unit, the general ward, the surgical ward and PICU were described. The mean stay (days), sex and mean age (years) of the admitted patients were analyzed. Data have been presented as divided between 4 monthly periods from March 12th (when Navarra entered in a situation of 
SARS-CoV-2 community transmission) to June 12th, 2020 [27]. All patients hospitalized in the pediatric ward had a negative SARS-CoV-2 PCR test prior to admission.

To describe in depth the characteristics of hospitalized patients, a more exhaustive sub-analysis was performed. April 2020 was chosen for this 4-week sub-analysis as it was the first complete month under the state of alarm, with schools closed and strict home confinement [6]. In this subgroup of patients, we retrospectively analyzed data from their digitalized medical history, including epidemiological data, reason for ED-consultation, reason for hospital admission, if they had previously consulted their pediatrician at their local health care center, diagnosis, mean hospital-stay, admission to PICU, and patient basal characteristics (age, sex, personal history, and previous illnesses). As "digestive pathologies" patients hospitalized due to acute gastroenteritis, vomiting, or non-surgical-abdominal pain were included. Acute bronchitis, respiratory distress, acute pneumonia, asthma or respiratory infections were included as "respiratory pathologies". As "neurological pathologies" seizures, epilepsy, headaches and neuromuscular disorders were included. As "nephrological pathologies" urinary tract infections or complications and as "haemato-oncological pathologies" admissions for oncologic treatments or oncologic-complications were included.

Analyses were performed using the statistical program STATA.12. The analysis of qualitative variables (sex, inclusion in the chronic circuit, PICU admission, a previous visit to their primary care center and diagnosis) was performed with Pearson's Chi-squared test. Whereas quantitative variables (age, days of admission, days in PICU and duration of symptoms before consulting to the ED) were analyzed with Student's $t$ test. To compare changes in proportions or percentages, a two-sample test of proportion analysis was performed. All statistical analyzes were performed with two tails, and a $P$ value of less than 0.05 was used as a point of statistical significance. The entire study was performed according to the Declaration of Helsinki of 1975 (October 2000 revision), the recommendations of the Spanish General Health Law on research and the ethical standards of the local ethics committee. The Ethics Committee of Navarra Health Department approved in May 2020 a study of the effects of COVID-19 on Navarra's pediatric patients [PI_2020/38: Estudio epidemiológico de las infecciones respiratorias por el nuevo Coronavirus (SARS-CoV-2) en población pediátrica].

\section{Results}

As described in Table 1, during the 4-month period analyzed in the ECIEN-2020 study (quarter March-June 2020), 10,298 children were attended in the CHN ED in 2019 compared to 3239 in 2020 , representing a statistically significant reduction in the ED consultations of $68 \%(P<0.001)$. The percentage of patients hospitalized among patients attended in the ED rose from 5.1\% in 2019 to $10.9 \%$ in 2020. In addition, the number of patients admitted in the short-stay ED unit decreased from 463 in 2019 to 113 in 2020, showing a $75 \%$ reduction $(P<0.001)$. In terms of hospital admissions, a total of 529 patients were admitted in the 2019 quarter, while 353 patients were admitted in the same period in 2020 , resulting in a $33 \%$ reduction in the number of total pediatric admissions in CHN $(P<0.001)$. The number of admissions in the CHN PICU dropped from 56 to 33 patients $(P=0.014)$. Mean age in the 2019 quarter of hospitalized children was 3.62 years compared to 3.99 years in 2020, and the average stay in 2019 quarter was 7.05 days compared to 7.10 days in 2020 . Both results not significantly different.

Table 1 Health assistance provided in the pediatric service of CHN Hospital in the four-month period March-June 2020 compared to 2019 quarter

\begin{tabular}{|c|c|c|c|c|c|c|c|c|c|c|c|c|}
\hline \multirow[t]{3}{*}{ Variables } & \multicolumn{8}{|c|}{ Monthly comparison } & \multicolumn{4}{|c|}{ Quarters comparison } \\
\hline & \multicolumn{2}{|l|}{ March } & \multicolumn{2}{|l|}{ April } & \multicolumn{2}{|l|}{ May } & \multicolumn{2}{|l|}{ June } & \multirow[t]{2}{*}{2019} & \multirow[t]{2}{*}{2020} & \multirow{2}{*}{$\begin{array}{l}\text { Percentage of } \\
\text { reduction, } \%\end{array}$} & \multirow[t]{2}{*}{$P$} \\
\hline & 2019 & 2020 & 2019 & 2020 & 2019 & 2020 & 2019 & 2020 & & & & \\
\hline \multicolumn{13}{|l|}{ Emergency department } \\
\hline Consultations, $n$ & 2301 & 693 & 3446 & 162 & 3232 & 1255 & 1319 & 511 & 10,298 & 3239 & 68 & $<0.001$ \\
\hline Observation unit, $n$ & 101 & 29 & 162 & 26 & 148 & 41 & 52 & 17 & 463 & 113 & 75 & $<0.001$ \\
\hline \multicolumn{13}{|l|}{ Admissions } \\
\hline General pediatric, $n$ & 112 & 75 & 179 & 122 & 166 & 114 & 72 & 42 & 529 & 353 & 33 & $<0.001$ \\
\hline PICU, $n$ & 8 & 5 & 16 & 12 & 20 & 8 & 12 & 8 & 56 & 33 & 59 & 0.014 \\
\hline Pediatric surgery, $n$ & 26 & 10 & 26 & 22 & 40 & 10 & 17 & 20 & 109 & 62 & 57 & $<0.001$ \\
\hline
\end{tabular}

ECIEN-2020 study: analysis of the effect of the COVID-19 pandemic. PICU pediatric intensive care unit, CHN Complejo Hospitalario de Navarra, COVID-19 coronavirus disease 2019 
Analyzing data on a monthly basis, consultations attended in the ED between March 12th and April 12th dropped a $70 \%$ in year 2020. This trend remained stable within the subsequent months analyzed (Table 1). Hospitalizations in the general pediatric ward also decreased from 112 to 75 admissions, representing a 33\% reduction. This reduction remained similar in the ECIEN study time period. Table 1 includes a monthly description of the admissions for nonCOVID-19 diseases in the general pediatric ward, the pediatric surgery ward and the PICU, in 2019 and 2020. The total number of ED consultations, general admissions and PICU admissions decreased during the pandemic-quarter, as shown in Fig. 1, but the percentage of PICU admissions among hospitalized patients did not suffer major changes ( $10.6 \%$ in 2019 vs. $9.9 \%$ in $2020, P=0.31$ ). No pediatric mortality was registered in the quarters analyzed.

A sub-analysis of hospital admissions during a 4-week period (April 2019 vs. April 2020) is displayed in Table 2. No significant changes have been found among the main patient's characteristics evaluated. Mean age was slightly lower in 2020 ( 4.1 vs. 3.5 years), with similar rates regarding sex, past medical history, previous diseases or inclusion in the chronic patient unit. No differences were found regarding the number of children who had consulted their primary health care center pediatrician prior consulting in the ED, nor regarding the percentage of children who required PICU admission (11.0\% in April 2019 vs. 17.5\% in 2020). Regarding admission data, no significant differences were observed in average hospital-stay ( 7.5 days in 2019 vs. 5.2 days in 2020). In 2020 patients tend to take longer to consult in the ED after symptom's onset (3.8 days in 2019 vs. 5.5 days in 2020), but no statistical significance was found. Regarding hospitalization cause, a clear reduction in pulmonary pathologies was noted, showing a 48\% decrease (from 63 to 11 admissions for respiratory pathology, $P=0.005$ ). In
2019, pulmonary diseases (such as acute bronchitis, asthma exacerbation, respiratory infections or pneumonia) were the reason for admission in more than half of the hospitalized cases, but it represented less than one-third of 2020 admissions. The percentage of admitted children with previous diseases and those included in the chronic children unit were also analyzed not finding significant changes $(55.9 \%$ and $14.4 \%$ in 2019 , respectively, vs. $55.0 \%$ and $12.5 \%$ in 2020 ). When analyzing admissions for other diseases, no significant differences have been found, although an increase in digestive pathology was detected (22.5\% in 2020 versus $11.9 \%$ in 2019). No mortality was recorded during the analyzed periods in the $\mathrm{CHN}$ pediatric department.

\section{Discussion}

The ECIEN-2020 study shows the complex effects of the COVID-19 pandemic and the multifactorial consequences of the preventive-measures adopted on pediatric hospital admissions in Navarra, Spain. These changes include the direct and indirect effects of the public health and social measures adopted (such as social distancing, strict homeconfinement and schools closures among others) as well as changes in parents' beliefs and concerns regarding the fear of attending a health center during the pandemic.

During the first wave of the COVID-19 pandemic, a noticeable decrease was observed in the total number of ED consultations (68\% reduction), as well as in the total number of hospital admissions (33\% reduction). Previous studies have been conducted, analyzing the reduction in ED consultations, and have published results similar to our data (64-76\% decrease in Italian hospitals) [10], but to our knowledge this is the first study to describe the influence of the COVID-19 pandemic on pediatric hospital admissions.
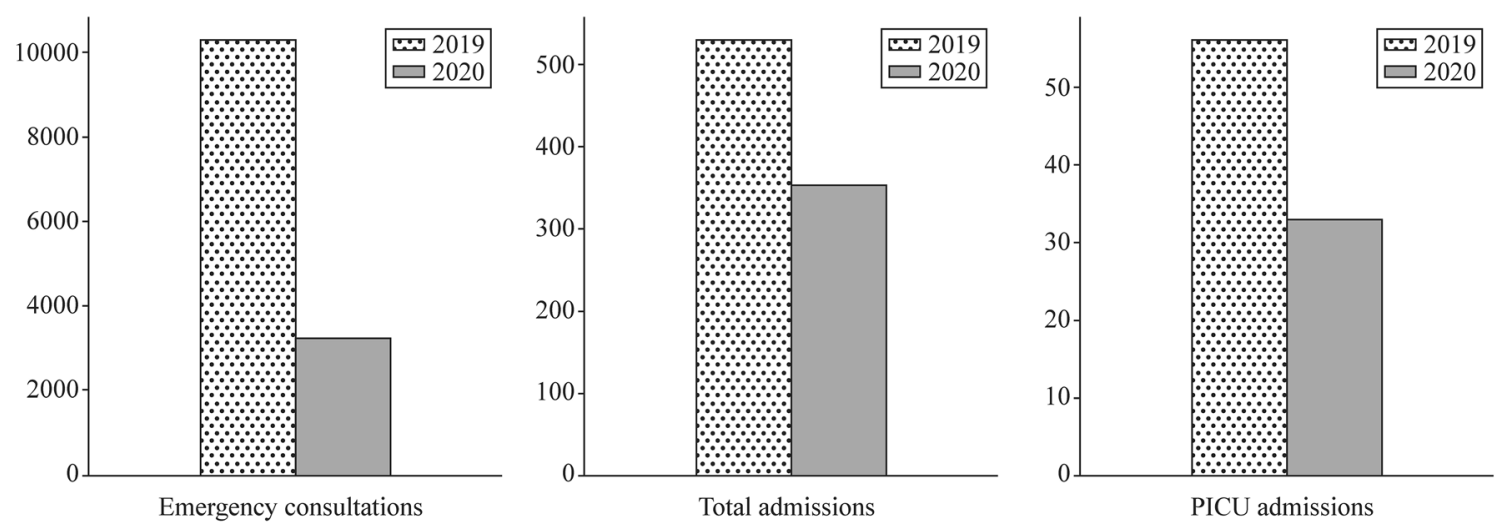

Fig. 1 Graphic representation of the pediatric medical attention during the fist wave of the COVID-19 pandemic in Navarra, Spain (March-June 2020). Data are compared with the same time period in the previous year
(March-June 2019): total emergency department consultations, admissions in the pediatric ward and PICU admissions (ECIEN-2020 study). COVID-19 coronavirus disease 2019, PICU pediatric intensive care unit 
Table 2 Clinical and socio-demographic characteristics of pediatric admissions in CHN Hospital in Navarra, Spain, during a one-month period

\begin{tabular}{|c|c|c|c|}
\hline Variables & April 2019 & April 2020 & $P$ \\
\hline CHN pediatric ward admissions, $n$ & 118 & 40 & $<0.001$ \\
\hline \multicolumn{4}{|l|}{ Patients characteristics } \\
\hline Sex, $n$ (\% males) & $70(59.3)$ & $25(62.5)$ & 0.72 \\
\hline Age $(y)$, mean \pm SD & $4.1 \pm 4.4$ & $3.5 \pm 3.7$ & 0.47 \\
\hline Personal history, $n$ ( $\%$ positives) & $66(55.9)$ & $22(55.0)$ & 0.81 \\
\hline Chronic patient unit, $n$ ( $\%$ included) & $17(14.4)$ & $5(12.5)$ & 0.75 \\
\hline \multicolumn{4}{|l|}{ Diseases characteristics } \\
\hline Previous consultation in PHCC, $n(\%)$ & $61(51.7)$ & $20(50.0)$ & 0.85 \\
\hline Previous symptoms duration $(\mathrm{d})$, mean \pm SD & $3.8 \pm 5.2$ & $5.5 \pm 8.2$ & 0.13 \\
\hline \multicolumn{4}{|l|}{ Pathology, $n(\%)$} \\
\hline Pulmonary & $63(53.4)$ & $11(27.5)$ & 0.005 \\
\hline Digestive & $14(11.9)$ & $9(22.5)$ & 0.10 \\
\hline Neurological & $14(11.9)$ & $6(15.0)$ & 0.61 \\
\hline Nephrological & $12(10.2)$ & $4(10.0)$ & 0.98 \\
\hline Endrocrinological & $4(3.4)$ & $1(2.5)$ & 0.78 \\
\hline Cardiological & $1(0.8)$ & $2(5.0)$ & 0.10 \\
\hline Hemato-oncological & $9(7.6)$ & $5(12.5)$ & 0.35 \\
\hline Others & $1(0.8)$ & $2(5.0)$ & 0.10 \\
\hline \multicolumn{4}{|l|}{ Admissions characteristics } \\
\hline Average stay $(d)$, mean \pm SD & $7.5 \pm 20.0$ & $5.2 \pm 5.6$ & 0.48 \\
\hline \multicolumn{4}{|l|}{$\mathrm{PICU}$} \\
\hline Admission in PICU, $n(\%)$ & $13(11.0)$ & $7(17.5)$ & 0.31 \\
\hline Average stay $(\mathrm{d})$, mean \pm SD & $0.4 \pm 1.3$ & $0.5 \pm 1.6$ & 0.73 \\
\hline
\end{tabular}

ECIEN-2020 study: comparison of April-2020 (COVID-19 pandemic and Spanish state of alarm) with April-2019 (control period). PHCC primary health care center, PICU pediatric intensive care unit, CHN Complejo Hospitalario de Navarra, COVID-19 coronavirus disease 2019

The significant decline found in ED consultations can be explained by several reasons. On the one hand, patients' fear of contagion in hospitals; on the other hand, a possible reduction in the number of infectious diseases as a result of SARS-CoV-2 preventive measures (facial masks, hand washing, social distancing, schools' closures, etc.). The reduction seen in the number of ED consultations may be related to the fact that many consultations usually attended in the public pediatric ED imply mild clinical symptoms and non-urgent pathologies; hence not really subsidiary of hospital care. Out of the total ED consultations, 5.1\% of patients were admitted in the general pediatric ward in 2019, whereas this percentage doubled in 2020. We believe this increase in the percentage of admission among ED users, is probably secondary to a reduction in the number of mildly sick children in the ED and to the complex changes in behaviors and concerns during a pandemic situation, as previously suggested by other authors [23]. Regarding the decrease detected in the total number of hospital admissions, the reduction in patients hospitalized for pulmonary diseases must be highlighted. This may be due to an indirect decline in other common respiratory infections (influenzae and other respiratory viruses) after the implementation of hygiene and social recommendations against SARS-CoV-2. Hygiene measures have proven to be effective in reducing pulmonary diseases in children [29]; in fact, no reduction has been found regarding other causes of admissions less dependent on interpersonal contact. The total number of ED consultations, general admissions and PICU admissions decreased during the pandemic-quarter as shown in Fig. 1, but the percentage of PICU admissions among hospitalized patients did not suffer major changes (10.6\% in 2019 vs. $9.9 \%$ in 2020), and no pediatric mortality was detected. It could be inferred that the reduction detected in the number of ED consultations and admissions was not associated with a worse evolution or prognosis of admitted patients, although a low statistical power due to the small sample size may also be considered.

To our knowledge, this is the first study describing the impact of this pandemic on hospital admissions in children. Navarra has been one of the most affected regions by COVID-19 in Spain [28, 30], but thanks to a great effort in resources organization the CHN Hospital did not collapse and no pediatric patient needed to be transferred outside the community for hospitalization during the pandemic. No significant changes were performed in the CHN 
pediatric service or in the staff usually attending pediatric patients to increase the hospital capacity during the pandemic. Only some ENT and some elective surgeries were cancelled. Navarra has a well-developed and centralized digital clinical history, allowing retrospective data revision from care health centers, emergency departments and hospitalization areas. The study was conducted in the referral pediatric hospital in Navarra, where COVID-19 and nonCOVID-19 patients were admitted.

As a possible limitation of our study, an insufficient sample size could be considered as a reason for the lack of differences found regarding some of the analyzed data. However, a statistically significant decrease in ED consultations, total admissions and admissions for the pulmonary disease has been found despite this possible limitation. In addition, the ECIEN-2020 study did not collect data from secondary or private hospitals in the community, but all hospitals reported to have noticed a decrease in their ED and in their pediatric admissions. Finally, the study has been performed comparing data collected during 2020 (the pandemic year) with 2019 (the previous year), which may lead to errors due to normal season variability.

In conclusion, the ECIEN-2020 study describes how the COVID-19 pandemic and the public health and social measures adopted during lockdown caused an important decrease in pediatric ED consultations and in pediatric hospital admissions, in particular in hospitalizations due to respiratory diseases. This reduction was not associated with worst clinical evolution, longer hospital stays, higher mortality rates or higher PICU admissions. It is advisable to conduct further studies including comparisons with multiple seasons, bigger sample sizes, and multicenter or meta-analysis studies, to confirm these results and to better understand these findings.

\footnotetext{
Author contributions RLB contributed to conception and design, analysis, and a draft of the manuscript. HAM contributed to conception and design, acquisition and analysis, and a draft of the manuscript. CGC contributed to acquisition and critical revision of the manuscript. ILMA contributed to design, acquisition, and a draft of the manuscript. GEE contributed to design, acquisition, and critical revision of the manuscript. MGL contributed to conception and design, acquisition, and critical revision of the final manuscript. All authors have agreed to submit this article in the present form. Each has participated sufficiently in the conception and design of the work. All authors approved the final manuscript as submitted and agree to be accountable for all aspects of the work.
}

Funding No funding was secured for this study.

\section{Compliance with ethical standards}

Ethical approval The local ethics committee approved on May 2020 the study "Comite de Etica del Complejo Hospitalario de Navarra" (CHN:
PI_2020/38: Estudio epidemiológico de las infecciones respiratorias por el nuevo Coronavirus SARS-CoV-2 en población pediátrica).

Conflict of interest All authors declare that they have no conflict of interest related to the publication of this study.

\section{References}

1. World Health Organization. Statement on the second meeting of the International Health Regulations. Emergency Committee regarding the outbreak of novel coronavirus (2019-nCoV). 2005. https://www.who.int/news-room/detail/30-01-2020-statementon-the-second-meeting-of-the-international-health-regulation s-(2005)-emergency-committee-regarding-the-outbreak-of-novel -coronavirus-(2019-nCov). Accessed 24 Jul 2020.

2. Blumenthal D, Fowler EJ, Abrams M, Collins SR. COVID19-implications for the health care system. N Engl J Med. 2020;383:1483-8.

3. Khullar D, Bond AM, Schpero WL. COVID-19 and the financial health of US hospitals. JAMA. 2020;323:2127-8.

4. Zhou P, Yang XL, Wang XG, Hu B, Zhang L, Zhang W, et al. A pneumonia outbreak associated with a new coronavirus of probable bat origin. Nature. 2020;579:270-3.

5. Ministry of the Presidency. Royal Decree 463/2020. Volume 67, Official State Bulletin. 2020. https://www.boe.es/buscar/pdf/2020/ BOE-A-2020-3692-consolidado.pdf. Accessed 24 Jul 2020 (in Spanish).

6. Sánchez-Villena AR, de La Fuente-Figuerola V. COVID-19: quarantine, isolation, social distancing and lockdown: are they the same? An Pediatr (Barc). 2020;93:73-4.

7. Roberts MG. The pluses and minuses of $\mathrm{R}_{0}$. J R Soc Interface. 2007;4:949-61.

8. Zhu N, Zhang D, Wang W, Li X, Yang B, Song J, et al. A novel coronavirus from patients with pneumonia in China, 2019. N Engl J Med. 2020;382:727-33.

9. Wang C, Horby PW, Hayden FG, Gao GF. A novel coronavirus outbreak of global health concern. Lancet. 2020;395:470-3.

10. Scaramuzza A, Tagliaferri F, Bonetti L, Soliani M, Morotti F, Bellone $\mathrm{S}$, et al. Changing admission patterns in paediatric emergency departments during the COVID-19 pandemic. Arch Dis Child. 2020;105:704-6.

11. Dong Y, Mo X, Hu Y, Qi X, Jiang F, Jiang Z, et al. Epidemiology of COVID-19 among children in China. Pediatrics. 2020;145:e20200702.

12. Cai J, Xu J, Lin D, Yang Z, Xu L, Qu Z, et al. A case series of children with 2019 novel coronavirus infection: clinical and epidemiological features. Clin Infect Dis. 2020;71:1547-51.

13. Liu W, Zhang Q, Chen J, Xiang R, Song H, Shu S, et al. Detection of Covid-19 in children in early January 2020 in Wuhan, China. N Engl J Med. 2020;382:1370-1.

14. Calvo C, García LHM, de Carlos VJC, Vázquez MJL, Spanish Paediatric Association Working Group on COVID-19 in Collaboration with the Health Ministry. Recommendations on the clinical management of the COVID-19 infection by the «new coronavirus» SARS-CoV2. Spanish Paediatric Association working group. An Pediatr (Engl Ed). 2020;92:241.e1-11 (in English, Spanish).

15. Tagarro A, Epalza C, Santos M, Sanz-Santaeufemia FJ, Otheo E, Moraleda C, et al. Screening and severity of coronavirus disease 2019 (COVID-19) in children in Madrid, Spain. JAMA Pediatr. 2020. https://doi.org/10.1001/jamapediatrics.2020.1346.

16. Wei M, Yuan J, Liu Y, Fu T, Yu X, Zhang ZJ. Novel coronavirus infection in hospitalized infants under 1 year of age in China. JAMA. 2020;323:1313-4. 
17. Lu X, Zhang L, Du H, Zhang J, Li YY, Qu J, et al. SARS-CoV-2 infection in children. N Engl J Med. 2020;382:1663-5.

18. Chen ZM, Fu JF, Shu Q, Chen YH, Hua CZ, Li FB, et al. Diagnosis and treatment recommendations for pediatric respiratory infection caused by the 2019 novel coronavirus. World J Pediatr. 2020;16:240-6.

19. Moreno-Galarraga L, Urretavizcaya-Martínez M, Echauri JA, Howard MG, García ER, Aguilera-Albesa S, et al. SARSCoV-2 infection in children requiring hospitalization: the experience of Navarra, Spain. World J Pediatr. 2020;16:614-22.

20. García-howard M, Herranz-aguirre M, Moreno-Galarraga L, Urretavizcaya-Martínez M, Alegría-Echauri J, Gorría-Redondo $\mathrm{N}$, et al. Case report: benign infantile seizures temporally associated with COVID-19. Front Pediatr. 2020;8:507.

21. Gutierrez-Jimeno M, Sada AI, Gavira JJ, Cebrian-Nebot C, de Aguilar VA. Severe cardiac and abdominal manifestations without lung involvement in a child with COVID-19. Intern J Clin Pediatr. 2020;9:92-7.

22. Moreno-Galarraga L, Taveras EM. COVID-19 disease in children: not as mild as we have been led to believe. World J Pediatr. 2020;16:426-7.

23. Isba R, Edge R, Jenner R, Broughton E, Francis N, Butler J. Where have all the children gone? Decreases in paediatric emergency department attendances at the start of the COVID-19 pandemic of 2020. Arch Dis Child. 2020;105:704.

24. Luna Tomás MA, Margelí Vila M, Ríos GC. Influence of the 2019-novel coronavirus pandemic on the management of breast cancer. Clin Invest Ginecol Obstet. 2020;47:89-90.

25. Velayos M, Muñoz-Serrano AJ, Estefanía-Fernández K, Sarmiento-Caldas MC, Moratilla-Lapeña L, López-Santamaría M, et al.
Influence of the coronavirus 2 (SARS-CoV-2) pandemic on acute appendicitis. An Pediatr (Engl Ed). 2020;93:118-22.

26. Navarre Institute of Statistics. Autonomous Community of Navarre. Provisional data January. 2020. https://www.navarra.es/ home_es/Gobierno+de+Navarra/Organigrama/Los+departamen tos/Economia $+\mathrm{y}+$ Hacienda/Organigrama/Estructura+Organica/ Instituto+Estadistica/. Accessed 24 Jul 2020 (in Spanish).

27. Government of Navarre. Impact and situation-coronavirus. Navarre's Open Government. 2020. https://gobiernoabierto.navar ra.es/es/coronavirus/impacto-situacion. Accessed 24 Jul 2020 (in Spanish).

28. Institute of Public Health and Labor of Navarra. Progress report COVID-19-20200412. 2020;2:1-2028. http://www.navar ra.es/home_es/Gobierno+de+Navarra/Epidemiologia/Infor mesVigilanciaEpidemiologia2020.htm. Acceseed 1 Sep 2020 (in Spanish).

29. Willmott M, Nicholson A, Busse H, Macarthur GJ, Brookes S, Campbell R. Effectiveness of hand hygiene interventions in reducing illness absence among children in educational settings: a systematic review and meta-analysis. Arch Dis Child. 2016;101:42-50.

30. Pollán M, Pérez-Gómez B, Pastor-Barriuso R, Oteo J, Hernán MA, Pérez-Olmeda M, et al. Prevalence of SARS-CoV-2 in Spain (ENE-COVID): a nationwide, population-based seroepidemiological study. Lancet. 2020;396:535-44.

Publisher's Note Springer Nature remains neutral with regard to jurisdictional claims in published maps and institutional affiliations. 